\title{
Apoptosis signaling pathways and lymphocyte homeostasis
}

\author{
Guangwu Xu ${ }^{1}$, Yufang Shi ${ }^{1}$ \\ ${ }^{I}$ Department of Molecular Genetics, Microbiology and Immunology, Robert Wood Johnson Medical School, University of Medicine \\ and Dentistry of New Jersey, 661 Hoes Lane, Piscataway, NJ 08854, USA
}

It has been almost three decades since the term "apoptosis" was first coined to describe a unique form of cell death that involves orderly, gene-dependent cell disintegration. It is now well accepted that apoptosis is an essential life process for metazoan animals and is critical for the formation and function of tissues and organs. In the adult mammalian body, apoptosis is especially important for proper functioning of the immune system. In recent years, along with the rapid advancement of molecular and cellular biology, great progress has been made in understanding the mechanisms leading to apoptosis. It is generally accepted that there are two major pathways of apoptotic cell death induction: extrinsic signaling through death receptors that leads to the formation of the death-inducing signaling complex (DISC), and intrinsic signaling mainly through mitochondria which leads to the formation of the apoptosome. Formation of the DISC or apoptosome, respectively, activates initiator and common effector caspases that execute the apoptosis process. In the immune system, both pathways operate; however, it is not known whether they are sufficient to maintain lymphocyte homeostasis. Recently, new apoptotic mechanisms including caspase-independent pathways and granzyme-initiated pathways have been shown to exist in lymphocytes. This review will summarize our understanding of the mechanisms that control the homeostasis of various lymphocyte populations.

Keywords: apoptosis, lymphocyte homeostasis, death-inducing signaling complex, apoptosome, signaling

Cell Research (2007) 17:759-771. doi: 10.1038/cr.2007.52; published online 19 June 2007

\section{Apoptotic cell death}

Apoptosis is a distinctive form of cell death [1] exhibiting specific morphological and biochemical characteristics, including cell membrane blebbing, chromatin condensation, genomic DNA fragmentation, and exposure of specific phagocytosis signaling molecules on the cell surface [2]. Cells undergoing apoptosis differ from those dying through necrosis. Necrotic cells are usually recognized by the immune system as a danger signal and, thus, resulting in inflammation; in contrast, apoptotic death is quiet and orderly. It is believed that most cell death in metazoan organisms occurs through apoptosis; apoptosis is critical in

Correspondence: Yufang Shi

Tel: +1-732-235-4501; Fax: +1-732-325-4505

E-mail: shiyu@umdnj.edu the formation of organs, limbs and other body structures, and in maintaining the function of most of the systems in an adult body. Therefore, dysregulation of the apoptotic signaling processes often leads to serious consequences, such as neurodegenerative diseases [3], cancer [4], or autoimmunity [5].

Our initial understanding of the molecular mechanisms that control apoptosis came from early studies using the nematode Caenorhabditis elegans [6-10]; these mechanisms were then extended to mammalian systems. A multitude of proteins and enzymes have now been identified that are involved in the initiation, amplification, or suppression of apoptosis. In most cells, apoptosis triggers usually lead to the activation of caspases, which ultimately mediate the autodestruction of the cell. Caspases normally exist as inactive precursors, called procaspases, which are cleaved to give rise to the active form. The preferred cleavage site for the known caspases is at the $\mathrm{C}$-terminal side of a four 


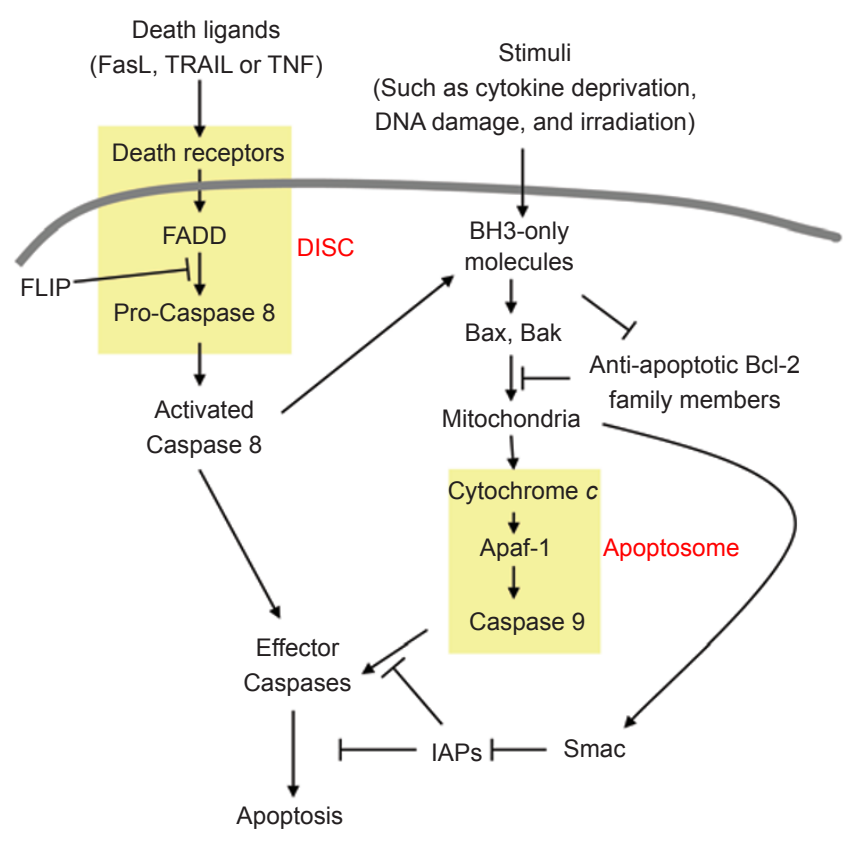

Figure 1 Schematic diagram of pathways to apoptosis. The left side shows the extrinsic apoptotic signaling pathway, and the right side shows the intrinsic apoptotic signaling pathway. These pathways converge at the activation of caspases. DISC and apoptosome are highlighted in yellow.

amino-acid motif, $\mathrm{X}$-X-X-Asp (where $\mathrm{X}$ can be any amino acid). Activated caspases in turn cleave various intracellular and cytoplasmic membrane substrates [11], leading to cellular disintegration.

There are two major pathways leading to apoptosis in the mammalian system: an extrinsic pathway initiated by death receptors and an intrinsic pathway that occurs through the mitochondria (Figure 1). The extrinsic pathway depends on binding of appropriate exogenous mediators to death receptors at the cell surface. In contrast, the intrinsic pathway responds to signals from within the cell, such as damages caused by radiation and various chemotherapeutic agents, to induce apoptotic signaling via the release of mitochondrial factors.

\section{Extrinsic apoptosis signaling pathways}

The extrinsic pathway of apoptosis signaling is initiated when death receptors at the cell surface encounter specific cognate "death ligands," inducing a conformational change that is transmitted through the cell membrane. These receptors can activate caspases within seconds of ligand binding and lead to apoptotic cell death in a matter of hours. Three major specific cell death receptor/ligand pairs have been de- scribed, all members of the Tumor Necrosis Factor Receptor Superfamily (TNFRSF): (1) Fas and Fas ligand (FasL) (Fas is also called Apo-1, CD95 or TNFRSF6 [12]; FasL is also called CD178,CD95L or TNFSF6 [13]); (2) "death receptors" (DR4 and DR5) and TNF-related apoptosis inducing ligand (TRAIL, also called Apo2L or TNFSF10) $[14,15]$; and (3) TNF $\alpha$ and the TNF receptor (TNF-R1). These death receptors, all members of the TNFRSF, are type I integral receptors with a conserved extracellular domain containing two to four cysteine-rich pseudo-repeats [16], a single transmembrane region, and a conserved intracellular "death domain" (DD) of about 80 amino acids that interacts with adaptor proteins [17].

Apoptosis-inducing receptors of the TNFR superfamily exist at the cell surface as pre-formed trimers. Ligation of the death receptors leads to apoptosis through a common transcription/translation-independent pathway: ligand binding induces the formation of the death-inducing signaling complex (DISC), which in turn cleaves and activates the initiator caspases (caspase 8 or 10). The initiator caspases in turn activate a second group of caspases, known as effector caspases, by proteolytic cleavage at specific sites. Upon activation, the effector caspases culminate the apoptotic process through the degradation of key intracellular substrates.

\section{The Fas-FasL pathway}

Among all the cell death receptors, Fas is the most extensively studied. The specific interaction of Fas with its membrane-bound cognate ligand, FasL, triggers the aggregation of Fas trimers. This enables the DD in the cytoplasmic tail of Fas to immediately recruit the DISC [18]. The DISC is composed of Fas, an accessory protein called Fas-associated death domain (FADD) [19] and procaspase 8 . FADD is a universal adapter protein that mediates signaling by DD-containing members of the TNFRSF [20]. FADD harbors an N-terminal death effector domain (DED) along with a C-terminal DD. In response to receptor aggregation, FADD is recruited by Fas, an interaction that is coordinated through the highly conserved DD motif found in both proteins. The interaction of FADD and Fas through their C-terminal DDs unmasks the N-terminal DED of FADD, allowing it to recruit pro-caspase 8 to the Fas signaling complex [21,22]. The presence of functional FADD protein is critical for Fas-mediated apoptosis as the expression of a dominant-negative form of FADD completely abrogates Fas-induced cell death [23]. Moreover, in vivo studies revealed a substantial attenuation of lymphocyte death in mice lacking FADD [24]. Formation of the DISC triggers the self-cleavage of pro-caspase 8 into active caspase 8 . Activated caspase 8 (also called FADDlike IL-1 converting enzyme (FLICE)) then cleaves the 
downstream pro-caspases 3, 6, and 7. Activated caspase 3 cleaves a variety of cellular substrates, including DNA repair enzymes, cellular and nuclear structural proteins, and endonuclease inhibitors. Moreover, caspase 3 has the ability to activate other caspases, such as caspases 6 and 7 , normally found in their zymogenic forms, resulting in an amplification of cellular destruction that ensures full execution of Fas-induced apoptosis.

Molecules other than FADD and pro-caspase 8 may also be recruited in Fas-mediated apoptosis. Receptor-interacting protein (RIP) [25], RIP-associated ICH (ICE and ced-3 homolog)/CED-3-homologous protein with a DD (RAIDD) [26], and pro-caspase 2 [27] form another signaling cascade of the Fas-mediated death pathway. The RIP-RAIDD pathway might serve as a backup to the FADD-caspase 8 system. However, it does not normally represent a major Fas-mediated death pathway.

Every step in Fas-mediated apoptosis is regulated. The FasL gene is transcriptionally inactive in most cells. The regulation of FasL expression controls FasL/Fas-mediated biological effects, such as the activation-induced cell death (AICD) of CD4+ T cells. The induction of Fas expression requires only TCR-activated PKC, while FasL expression requires the activation of both $\mathrm{PKC}$ and NFAT, the latter by $\mathrm{Ca}^{2+}$ mobilization [28]. Regulation of Fas expression also controls Fas responses, for example, in p53-induced apoptosis. Stimulation of Fas by membrane-bound FasL can be antagonized by the soluble decoy receptor DcR3 in humans [29], by various Fas isoforms lacking the transmembrane and/or DDs, and by soluble inactive FasL. The caspase 8-activating capacity of the Fas-DISC complex is regulated mainly by an inhibitory protein called FLICE-like inhibitory protein (FLIP) [26, 30-33]. FLIP exists in several isoforms that are structurally similar to caspase 8 , but lacking in enzymatic activity [30]. Incorporation of FLIP into the DISC of death receptors disables DISC-mediated processing, thus preventing the activation caspase 8 [30]. In addition, Fas-mediated apoptosis is controlled by a host of regulators of the mitochondrial cell death pathway (see below), for example, by some Bcl-2 family members or inhibitor of apoptosis proteins (IAPs).

Fas-mediated cell death in T cells occurs not only by apoptosis but also by necrosis. Necrosis mediated by Fas requires FADD and RIP, whereas caspase 8 seems to be dispensable [34]. However, the molecular mechanisms linking Fas, FADD, and RIP in processing necrosis are not yet clear. Although Fas is recognized predominantly as a death inducer, it also triggers proliferative signals in $\mathrm{T}$ cells [35].

\section{The TRAIL-DR pathway}

Like other TNF family ligands, TRAIL exists as a type
II membrane-bound protein, or it can be cleaved from the membrane by cysteine proteases to generate a soluble form. Both human and mice have five receptors for TRAIL: the death-inducing receptors DR4 [36] and DR5 [9, 30, 37-39], and the decoy receptors DcR1 [30, 36, 39, 40], DcR2 [40-42] and OPG (osteoprotegerin) [43]. Among these receptors, only DR4 and DR5 have functional DDs that mediate apoptosis induction; the decoy receptors do not. DcR1 lacks both a DD and a transmembrane domain. It is anchored to the membrane via a glycophosphatidyl inositol tail. DcR2 has a truncated and nonfunctional DD. OPG is secreted as a dimeric soluble form, which also binds to RANKL. These decoy receptors bind to TRAIL, but do not transduce a signal, thus protecting cells from TRAIL-induced apoptosis by interrupting the formation of functional death receptor trimers. DISC formation and Bid cleavage downstream of DR4 and DR5 is similar to that seen in Fas-induced apoptosis. Briefly, TRAIL triggers clustering of DR4 or DR5, which recruits FADD and procaspase 8 to form the DISC. After the activation of caspase 8 , effector caspases are subsequently activated.

Both cell-bound TRAIL and genetically engineered soluble forms rapidly induced apoptosis in a wide variety of transformed cell lines of diverse origins [14, 41]. Since normal cells express decoy receptors, while tumor cells do not, it is believed that TRAIL may specifically kill tumor cells, but this remains controversial. There were reports suggesting that TRAIL therapy might cause hepatotoxicity $[44,45]$, and recombinant TRAIL was found to induce apoptosis in hepatocytes [45]. But a later study found that hepatotoxicity of recombinant TRAIL is due to the exogenous sequence tags [46].

TRAIL expression was significantly increased in epithelium, airway smooth muscle, vascular smooth muscle, and throughout the interstitial tissue of asthmatic patients compared to non-asthmatic subjects. Increased expression of the TRAIL decoy receptor DcR2 and decreased expression of the TRAIL receptors DR4 and DR5 were also observed in asthma patients. It has been suggested that modulation of TRAIL and TRAIL receptor interactions after antigen challenge may be crucial in promoting eosinophil survival in asthma [47].

\section{The TNF $\alpha-T N F R 1$ pathway}

$\mathrm{TNFa}$ is a multifunctional proinflammatory cytokine. It exists as a homotrimer of three 157-amino-acid peptide chains. TNF $\alpha$ exerts its function via two receptors: TNFR1 (also known as p55), which contains a DD [48-50], and TNFR2 (also known as p75), which lacks a DD [51, 52]. The initial step in TNFR1 signaling involves the binding of the TNF trimer to the extracellular domain of TNF-R1 and the release of the inhibitory protein, silencer of death 
domains, from TNF-R1's intracellular domain. The resulting aggregated TNF-R1 intracellular domain is recognized by the adaptor protein TNF receptor-associated death domain (TRADD), which recruits RIP, TNF-R-associated factor 2 (TRAF2), and FADD. These latter proteins recruit key enzymes to TNF-R1 that are responsible for initiating signaling events. Caspase 8 is recruited by FADD to the TNF-R1 complex, where it becomes activated by self-cleavage, and initiates a protease cascade leading to apoptosis. TRAF2 recruits cellular inhibitor of apoptosis protein-1 (cIAP-1) and cIAP-2. TRAF2 is also thought to activate MAPKKKs, such as extracellular signal-regulated kinase kinase kinase 1 (MEKK1) or ASK1, in a complex at or near the receptor, thereby activating a cascade of kinases resulting in the activation of JNK. The protein kinase RIP is critical to the functional activation of the transcription factor $\mathrm{NF}-\kappa \mathrm{B}$.

TNFR1-induced apoptosis involves two sequential signaling complexes. First, the binding of TNF to TNFR1 recruits TRADD, RIP1, and TRAF2 to form a plasma membrane bound complex (complex I consisting of TNFR1, TRADD, RIP1 and TRAF2), and rapidly signals activation of NF- $\kappa$ B. After forming complex I, TRADD and RIP1 become modified and dissociate from TNFR1, then TRADD (and or RIP1) binds to FADD resulting in recruitment of caspase $8 / 10$, forming a cytoplasmic complex (complex II consisting of TRADD, RIP1, FADD, and caspase 8/10) and leading to apoptosis. The FLIP levels determine if the latter complex forms. When NF- $\mathrm{BB}$ is successfully activated by complex I, cellular FLIP levels are sufficiently elevated to inhibit the formation of complex II and block apoptosis. If the initial signal by complex I fails to activate NF- $\kappa B$, complex II signals for apoptosis [53].

The biological outcome of TNF $\alpha$ ligation is determined by the balance between NF- $\mathrm{KB}$ and JNK signaling: NF$\kappa \mathrm{B}$ promotes survival, whereas JNK enhances cell death. TNF $\alpha$-mediated JNK activation accelerates turnover of the NF- $\kappa \mathrm{B}$-induced anti-apoptotic protein c-FLIP. JNK mediates phosphorylation and activation of the E3 ubiquitin ligase Itch, which specifically ubiquitinates c-FLIP and induces its proteasomal degradation. JNK1 or Itch deficiency or treatment with a JNK inhibitor makes mice resistant in three distinct models of TNF $\alpha$-induced acute liver failure, and cells from these mice do not display inducible c-FLIP ubiquitination and degradation [54].

Induction of apoptosis may not be the major physiological role of TNF $\alpha$. TNF $\alpha$ mediates the inflammatory response and regulates immune function through activation of transcription factors, NF- $\mathrm{kB}$ and c-Jun. Inappropriate production of TNF $\alpha$ or sustained activation of TNFR signaling has been implicated in the pathogenesis of a wide spectrum of human diseases, including autoimmune diseases such as multiple sclerosis $[55,56]$ and rheumatoid arthritis [57]. In fact, anti-TNF $\alpha$ therapy has become an effective treatment for these autoimmune disorders.

\section{Intrinsic signaling pathways}

The mitochondrial pathway of apoptosis in mammalian cells centers on a key event: mitochondrial outer membrane permeabilization (MOMP), considered the point-of-noreturn in apoptosis induction. Release of certain proteins from the mitochondrial intermembrane space due to MOMP triggers a cascade of caspase activation that results in irreversible events culminating in apoptosis.

MOMP is normally prevented by anti-apoptotic members of the Bcl-2 family, which is composed of both anti-apoptotic and pro-apoptotic proteins. Bcl-2 was first described as a unique oncogene in B cell lymphomas that acted to inhibit cell death [58-60]. Since the identification of Bcl2, numerous family members have been found. These proteins share up to four Bcl-2 homology domains (BH1 to $\mathrm{BH} 4)$. Bcl-2 family is generally divided into three subgroups based on their roles in apoptosis and the $\mathrm{BH}$ regions they shared: one anti-apoptotic group and two pro-apoptotic groups. The anti-apoptotic group contains Bcl-2, Bcl- $\mathrm{x}_{\mathrm{L}}[61]$, Bcl-w [62], Bcl-B [63], A1 [64] and Mcl-1 [65], which share three or four BH regions. One group of the pro-apoptotic Bcl-2 family members, including Bax [66], Bak [67, 68], Bcl- $\mathrm{x}_{\mathrm{s}}[61]$ Bok [69], and Bcl- $\mathrm{G}_{\mathrm{L}}$ [70], have two or three BH domains. The other group contains the $\mathrm{BH} 3$-only proteins, including Bad [71], Bid [72], Bim [73], Bik [74], Noxa [75], Puma [76], Bcl-Gs [70], Blk [77], Bmf [78] and Hrk [79], which share only the $\mathrm{BH} 3$ domain.

Among the pro-apoptotic proteins, Bax and Bak appear to be requisite for MOMP and are likely to directly mediate MOMP by forming size-indeterminate openings in the outer mitochondrial membrane [80]. Cells deficient in both Bax and Bak are resistant to many apoptotic stimuli that induce cell death through mitochondrial disruption $[81,82]$. Bax and Bak are present in most cells in inactive forms, and their activation is triggered directly or indirectly by other proteins, such as the BH3-only proteins. Once activated, Bax and Bak permeabilize the outer membrane of mitochondria, resulting in release of pro-apoptotic factors such as cytochrome $c$.

This activation of Bax and Bak is inhibited by the antiapoptotic Bcl-2 family proteins which either inhibit the apoptosis-activating $\mathrm{BH} 3$-only proteins or sequester Bax and Bak to prevent their activation. This restraint of Bax, Bak by anti-apoptotic Bcl-2 proteins can be reversed by the $\mathrm{BH} 3$-only proteins, as well as by protein modifications (such as phosphorylation or deamidation) of the anti-apoptotic proteins. 
BH3-only proteins serve as sensors for apoptotic stimuli [83]. Upon stimulation such as deprivation of cytokines, $\mathrm{BH} 3$-only proteins are activated. It is still a hotly debated issue whether $\mathrm{BH} 3$-only proteins activate Bax and Bak directly $[84,85]$ or whether they do so indirectly by their binding to anti-apoptotic Bcl-2 proteins that normally sequester Bax and Bak [86, 87].

Once MOMP occurs, proteins in the intermembrane space are released to the cytosol. One such protein, cytochrome $c$ [88], binds to cytosolic, monomeric apoptotic protease activating factor-1 (APAF-1) at its WD40 domain. This interaction with cytochrome $c$ induces a conformational change in APAF-1, promoting APAF-1 oligomerization to initiate apoptosome formation $[26,89,90]$. The apoptosome then binds to the proform of caspase 9 , the initiator caspase of the intrinsic pathway, via the caspase recruitment domains in both APAF-1 and pro-caspase 9. The oligomerization of pro-caspase 9 on the apoptosome triggers auto-cleavage, possibly by simply bringing pro-caspase 9 molecules into proximity, giving rise to active caspase 9. Interestingly, recently it was found that acetylcholinesterase is important in apoptosis [91], as it plays a pivotal role in the formation of apoptosome [92, 93]. Active caspase 9 then cleaves the effector caspases, such as caspase 3 and caspase 7, resulting in their activation. Recently, it was found that intracellular nucleotides can bind to cytochrome $c$ and prevent the formation of apoptosome. To undergo apoptosis, cells might need to break this nucleotide shield. It is not known how this is achieved [94]. However, it is also possible that cells might undergo apoptosis without breaking down the nucleotide shield. It was found that although APAF-1 is required for mitochondrial apoptosis [95], cytochrome $c$ and the apoptosome are not always required for caspase 9 activation, since caspase 9 can also be activated in mice bearing the cytochrome $c$ that is deficient in the apoptosis inducing function [96].

The process of apoptosis downstream of MOMP is regulated at the level of the apoptosome and at each of the subsequently activated caspases. Caspase activity can be modulated by caspase-binding proteins of the inhibitor of apoptosis proteins (IAPs) family [97, 98]. For example, human X-linked IAP (XIAP) directly inhibits at minimum, caspases 3 and 7 [99]. Overexpression of these pro-survival molecules, including XIAP [98] and surviving [100], is observed in many human tumors. Additionally, these caspase inhibitors can be antagonized by the pro-apoptotic protein, second mitochondria-derived activator of caspase/direct IAP-binding protein with low pI (SMAC/DIABLO) [101, 102]. SMAC/DIABLO can displace XIAP from its interaction with activated caspase 3 , allowing cell death to proceed. Thus, both the activation and function of caspases can be regulated through multiple binding proteins.
Another mithochondrial component with a regulatory role in apoptosis is the apoptosis inducing factor (AIF) [103]. AIF has homology to bacterial oxidoreductases and is normally localized in the mitochondria, but translocates to the cytoplasm during apoptosis. Apoptosis induced by AIF cannot be inhibited by the caspase inhibitors, and can result in nuclear condensation and fragmentation independent of other pro-apoptotic factors. Interestingly, the redox-active enzymatic region of AIF is anti-apoptotic, giving the molecule a dual role in cell survival and cell death. The detailed pathways of caspase-independent apoptosis are poorly understood.

The intrinsic and extrinsic pathways are used for the sake of description. Actually, there is cross-talk between these pathways. Depending on the cell types and stimuli and other environmental factors, different apoptotic pathways play different roles. For example, in cells where there is no sufficient amount of activated caspase 8 allowing direct cleavage and activation of effector caspases, cleavage of the BH3-only protein Bid by caspase 8 might become a major pathway (Figure 1). This cleavage of Bid produces the pro-apoptotic tBID fragment that induces cytochrome $c$ release from mitochondria and caspase 9 activation [104, 105]. Caspase 9 can then cleave caspase 8, thus forming a positive feedback loop that amplifies the original signal from caspase 8.

\section{Other apoptosis pathways}

The granzymes form a family of serine proteases, different from the caspases, that also induce cell death. T cells and natural killer cells utilize a granule-exocytosis pathway to eliminate virus-infected cells. Cytotoxic granules deliver perforin and granzymes to the target cells through yet unidentified pathways. The apoptotic signaling processes triggered by each granzyme species are relatively distinct. Granzyme B triggers apoptosis via caspase-dependent and -independent mechanisms [106] that involve direct cleavage of downstream caspase substrates. Granzyme B has been shown to cleave caspase 3, caspase 8 [18] and other substrates, including Bid and ICAD (inhibitor of caspaseactivated deoxyribonuclease), which results in activation of the CAD endonuclease. Granzyme A induces cell death via a caspase-independent pathway by inducing single-strand DNA nicks. It targets the SET complex (a 270 to $420-\mathrm{kDa}$ endoplasmic reticulum-associated complex) resulting in the degradation of selected components, freeing the NM23-H1 DNase and resulting in single-stranded DNA nicks [107]. The granzymes were recently shown to induce apoptosis in the cells harboring them [108].

Another family of apoptosis-mediating cysteine proteases - the calpains (calcium-activated neutral proteases) 
- are non-lysosomal intracellular cysteine proteases. The mammalian calpains include two ubiquitous proteins, CAPN1 and CAPN2, two stomach-specific proteins, and CAPN3, which is muscle-specific. Calpains also share some common substrates with caspases [109]. Furthermore, purified calpain enzymes cleaved Bax in a calcium-dependent manner [110]. It has been shown that neutrophils require calpains for BAX activation and apoptosis [111, 112]. Recently, it has been shown that there is cross-talk between the caspases and the calpains [113, 114]. Further elucidation of protease-induced cell death should uncover caspase-independent programs.

\section{Apoptosis in lymphocytes}

Apoptosis in T cells plays a key role in their development, differentiation, and homeostasis. Several mechanisms are involved in controlling apoptosis of different subpopulations of T cells; even the same subpopulation can use different mechanisms under different circumstances.

\section{Intrathymic selection}

It has long been shown that apoptosis plays a crucial role in intrathymic selection of $\mathrm{T}$ cells during their development. It is generally believed that immature $\mathrm{T}$ cells undergo apoptosis once they recognize self-antigens presented by self-MHC molecules, a process referred to as negative selection [115]. Although negative selection has been the focus of many prominent investigations, the molecular mechanisms controlling negative selection are still largely unknown.

The role of death receptors has been established in various cellular systems, but it remains controversial whether death receptors have a role in the negative selection of $\mathrm{T}$ cells in the thymus. TRAIL-/- mice showed increased numbers of immature thymocytes and decreased apoptosis of activated T cells induced by restimulation [116], while there was also evidence showing no defects in lymphoid or myeloid cell homeostasis or T cell function in TRAIL-/mice $[117,118]$. In addition, anti-CD3 stimulation induced cell death of thymocytes in vitro has been shown to be TRAIL-independent, since it could not be blocked by soluble DR5-Fc [119]. Although it has been shown that TNFR1 [120, 121], TNFR2 [122] or TNFR1 and TNFR2 double [123] deficient mice and Fas/FasL deficient mice [124-128] exhibited normal negative selection, there was also evidence supporting a role of TNF and Fas/FasL in negative selection in some models $[129,130]$. For example, overexpression of TNF in mice resulted in a small thymus with decreased populations of double positive thymocytes [131]. Nevertheless, negative selection is intact in mice lacking FADD or caspase $8[132,133]$, major signaling molecules in death receptor signal transduction, which suggests that death receptors are not important in negative selection. However, further systemic investigations are still needed to clarify the role of death receptors in negative selection and the models should be standardized as the use of different negative selection models sometimes led to discrepant conclusions [123].

\section{Activation-induced cell death}

The homeostasis of peripheral $\mathrm{T}$ cells, especially after activation by specific antigens, is maintained by AICD [134-136]. AICD plays a key role in controlling the vigorousness and persistence of immune responses. AICD has been shown to be mediated mainly by the extrinsic Fas/FasL pathway [137-140], since interference with the Fas/FasL interaction by soluble Fas-Fc fusion protein or neutralizing anti-FasL inhibited AICD, and Fas and FasL are upregulated shortly after TCR ligation. Some T cells do undergo apoptosis even with the blockade of Fas/FasL signaling, however, suggesting that Fas-independent pathways are also involved in the AICD of T cells [138]. AICD in T cells from AIDS patients was dependent on TRAIL, as it was blocked not by antibodies to Fas or FasL [141] but by the neutralizing antibody to TRAIL [142]. However, there were also conflicting data showing that there was upregulation of TRAIL receptors in peripheral T cells upon activation, but these cells remained resistant to TRAIL [119]. TNF has also been suggested by some studies to play a role in AICD $[126,143,144]$. It was found that TCR stimulation can induce the expression of TNF [145] and antibody to TNF can partially inhibit antigen induced cell death of T cells in vivo [126]. In addition, microinjection of antibody to TNF inhibited AICD induced by anti-CD3 in CD8 cells [143]. However, it has also been reported that TNFR:Fc fusion protein did not inhibit AICD of effector T cells [146].

The AICD we mentioned above was studied mainly in either bulk lymphocytes (unpurified lymphocytes, as opposed to purified subgroups of lymphocytes) or pure subgroup of lymphocytes from pathogen or antigen primed animals. It is conceivable that AICD induced in different types of lymphocytes and under different situations are mediated through different pathways. In the last two decades, there have been a huge amount of studies on AICD of lymphocytes. There are some discrepancies about the pathways involved in AICD of lymphocytes, which are largely due to the different models of AICD used. For example, the antigen or antibody, the duration and the doses of the stimulation and restimulation differed from experiments to experiments. The precise mechanisms involved in AICD of lymphocytes need further investigation. In the future, some standardized models might be used to dissect the apoptotic pathways involved in AICD of lymphocytes 
under normal or disease situations. In the following paragraphs, we will discuss AICD in some differentiated effector T-cell subgroups. These cells were differentiated under relatively standardized specific cytokine milieu. Pathways employed in AICD of these effector cells are sometimes different from those seen in AICD of bulk lymphocytes. Also, AICD in distinct effector cells are executed through different mechanisms (Table 1).

CD4+ T cells differentiate into either type I (Th1) and type II (Th2) helper T cells, depending on the cytokine environment during activation [147, 148]. Th1 cells evolved to clear intracellular pathogens and are defined on the basis of their production of interferon- $\gamma$ (IFN- $\gamma$ ). On the other hand, Th2 cells are critical for the control of certain parasitic infections and are defined by their production of cytokines IL-4, IL-5, and IL-13. While it is not clear whether the Fas/FasL interaction is involved in negative selection, it is quite certain that Fas/FasL contributes to the polarization of Th1 [149, 150]. Th1 cells are susceptible to AICD. They undergo rapid apoptosis upon the antigen stimulation. AICD in Th1 cells is mainly mediated by Fas/FasL. Th1 cells generated from gld or $l p r$ mice did not show rapid AICD compared to the Th1 cells from normal mice. Soluble Fas could block AICD in Th1 cells. Th2 cells also undergo AICD when stimulated with antigen. However, they died much slower and soluble Fas had limited effect on AICD in Th2 cells. Unlike Th1 cells, Th2 cells are resistant to Fas-mediated apoptosis [151, 152]; however, the underlying mechanism is controversial. Some studies indicated that Th2 cells express less Fas/FasL $[150,153]$. On the other hand, there was also evidence showing no difference in expression of Fas/FasL between Th1 and Th2 cells [154]. Furthermore, it was found that Th2 cells express high levels of FAP-1, an Fas-associated phosphatase that may act to inhibit Fas signaling [154]. Still, there are other data showing that selective upregulation of phosphatidylinositol 3-kinase activity in Th2 cells induced by TCR activation inhibited caspase 8 cleavage,

Table 1 AICD in main effector T-cell subgroups

\begin{tabular}{ll}
\hline T-cell subgroup & Pathway \\
\hline Bulk activated T cells & Fas/FasL \\
Th1 & Fas/FasL \\
Th2 & Granzyme B \\
Th17 & Fas/FasL? \\
Tc1 & Fas/FasL/Granzyme B \\
Tc2 & $?$ \\
Treg, $\gamma \delta$ T cells, NK, NKT & $?$ \\
\hline
\end{tabular}

which is believed to be a mechanism for Th2 resistance to Fas-mediated apoptosis $[155,156]$.

AICD in Th2 cells are less well studied compared to Th1 cells. For a long time, it has not been known what molecule(s) is responsible for AICD in Th2 cells. Recently, granzyme B was found to play a critical role [157]. Death receptors are not involved in AICD of Th2 cells since blocking their cognate ligands had no effect on apoptosis of activated Th2 cells. However, inhibition of granzyme $B$ activity abolished AICD in Th2 cells. Furthermore, Th2 cells derived from granzyme B-deficient mice were resistant to AICD. As a consequence, granzyme B deficiency or inhibition of granzyme B activity enhanced the production of Th2 cytokines and increased susceptibility to allergeninduced asthma.

Th17 (also called Thi), a new subgroup of effector T cells secreting IL-17, has been recently described $[158,159]$ and has generated significant interest. Th17 cells have been shown to play important roles in the pathogenesis of some immune-related diseases. Therefore, it would be interesting to examine how this critical T-cell population undergoes AICD. Recently, we found that neutralizing antibody to Fas largely blocked the AICD induced by anti-CD3 in Th17 cells, while blocking TRAIL and TNF did not show any effects (Yingyu Zhang and Guangwu Xu et al., paper in preparation). These results suggest that Fas/FasL might be the major pathway involved in the AICD of Th17 cells.

The Fas/Fas ligand system is involved in AICD of CD4+ $\mathrm{T}$ cells, but it seems not essential for $\mathrm{CD} 8+\mathrm{T}$ cell death [160]. Instead, apoptotic signaling through TNFR is likely engaged in AICD of CD8+ cells [143, 161]. A marked expansion and prolonged persistence of functional activated cytotoxic $\mathrm{T}$ cells was observed in mice lacking TNFR p55 [161]. In the study aimed at understanding the role of CD4+ T cell help in CD8+ T-cell memory, memory CD8+ $\mathrm{T}$ cells, without the appropriate CD4+ T-cell help, underwent AICD upon secondary stimulation. These unhelped CD8+ T cells synthesize TRAIL on antigen restimulation which mediated AICD [162]. However, it should be pointed out that memory CD8+ $\mathrm{T}$ cells are differentiated $\mathrm{CD} 8+\mathrm{T}$ cells. AICD in these cells might be different from that in the naïve CD8+ $\mathrm{T}$ cells or in vitro differentiated Tc cells. Recently, it was reported that depletion of granzyme B by RNA interference resulted in the suppression of procaspase 3 processing and tBid production and enhanced the survival of CD3-stimulated CD8+ T cells. Furthermore, this effect is independent of perforin status [163]. Taken together, the question of what constitutes the major pathway mediating AICD of CD8+ T cells needs further investigation.

Similar to their CD4+ counterparts, the existence of distinct subsets of CD8 $+\mathrm{T}$ cells has been established in mouse [164-166], rat [167, 168], and human [169-171]. 
They were termed Tc1 and Tc2. Tc1 cells secret IFN $\gamma$, while Tc2 cells secret IL-4, IL-5, IL-6, and IL-10 [164]. Limited data are available on AICD in Tc1 and Tc2. Like Th1 cells, Tc1 cells were also more susceptible to AICD than their type 2 counterparts and Fas/FasL plays important roles in AICD of Tc1 cells, as the neutralizing antibody to FasL partially abolished AICD in these cells. However, it was found that Granzyme B inhibitor (z-AAD-CMK) also inhibited AICD in Tc1 cells, indicating the involvement of the granule exocytosis mechanism in Tc1 AICD [146]. Further experiments in Granzyme B deficient mice will be helpful in understanding the role of granzyme B in Tc1 AICD. Though Tc2 are relatively resistant to Fas/FasLinduced apoptosis, cell-surface expression of Fas and FasL was found at similar levels on both subsets [146]. It is still unknown why Tc2 are relatively resistant to Fas/FasL-induced apoptosis and how AICD is regulated in Tc2 cells.

The apoptotic mechanisms employed by other subgroups of T cells, such as NKT cells and CD4+CD25+ regulatory $\mathrm{T}$ cells, are largely unknown; these cells, however, seem to be relatively resistant to apoptosis $[172,173]$. Freshly isolated regulatory $\mathrm{T}$ cells are highly sensitive to CD95mediated apoptosis, but upon TCR restimulation, regulatory $\mathrm{T}$ cells displayed a reduced sensitivity toward AICD compared with CD4+CD25-T cells [174]. Since these cells are important in innate immunity and immune regulation, studying their AICD will provide novel information for the understanding of the immune system.

Compared to what we know about AICD in T cells, much less is known about B cell apoptosis. Like in T cells, cell death induced by activation via the $\mathrm{B}$ cell receptor has also been referred to as AICD $[175,176]$. Unlike in T cells, however, AICD in B cells is almost independent of death receptors, and is instead dependent on the intrinsic pathway [177]. Blocking the Fas/FasL system or preventing FADD signaling by inhibitors like FADD/MORT1 or CrmA did not block AICD in B cells. Furthermore, Fas deficient lpr mice showed BCR ligation-induced B cell death that was similar to their wild-type counterparts [178-180]. BCR crosslinking leads to morphological changes in mitochondria, including extensive disruption of the mitochondria membrane and swelling of mitochondria during BCR-induced apoptosis [181]; it also results in depolarization of mitochondrial membrane potential [182-184]. Furthermore, mitochondrial inhibitors, which can stabilize mitochondrial membrane potential, are able to protect B cells from AICD [181, 185]. Still, many details of the regulation of mitochondria signaling in B cell AICD remain unknown.

The mechanisms that control apoptosis in various lymphocyte populations are clearly different. These differences are beginning to be recognized and have attracted the attention of immunologists. Further studies in this exciting area will undoubtedly reveal novel information that will advance our understanding of the immune system and its regulatory mechanisms.

\section{References}

1 Lockshin RA, Williams CM. Programmed cell death - I. Cytology of degeneration in the intersegmental muscles of the Pernyi silkmoth. J Insect Physiol 1965; 11:123-133.

2 Kerr JF, Wyllie AH, Currie AR. Apoptosis: a basic biological phenomenon with wide-ranging implications in tissue kinetics. Br J Cancer 1972; 26:239-257.

3 Ekshyyan O, Aw TY. Apoptosis: a key in neurodegenerative disorders. Curr Neurovasc Res 2004; 1:355-371.

4 Vermeulen K, Van Bockstaele DR, Berneman ZN. Apoptosis: mechanisms and relevance in cancer. Ann Hematol 2005; 84:627639.

5 Mahoney JA, Rosen A. Apoptosis and autoimmunity. Curr Opin Immunol 2005; 17:583-588.

6 Hengartner MO, Horvitz HR. C. elegans cell survival gene ced-9 encodes a functional homolog of the mammalian proto-oncogene bcl-2. Cell 1994; 76:665-676.

7 Chinnaiyan AM, Chaudhary D, O'Rourke K, Koonin EV, Dixit VM. Role of CED-4 in the activation of CED-3. Nature 1997; 388:728-729.

8 Duan H, Dixit VM. RAIDD is a new "death" adaptor molecule. Nature 1997; 385:86-89.

9 Wu D, Wallen HD, Inohara N, Nunez G. Interaction and regulation of the Caenorhabditis elegans death protease CED-3 by CED-4 and CED-9. J Biol Chem 19 97; 272:21449-21454.

10 Spector MS, Desnoyers S, Hoeppner DJ, Hengartner MO. Interaction between the C. elegans cell-death regulators CED-9 and CED-4. Nature 1997; 385:653-656.

11 Nicholson DW. Caspase structure, proteolytic substrates, and function during apoptotic cell death. Cell Death Differ 1999; 6:1028-1042.

12 Itoh N, Yonehara S, Ishii A, et al. The polypeptide encoded by the cDNA for human cell surface antigen Fas can mediate apoptosis. Cell 1991; 66:233-243.

13 Suda T, Takahashi T, Golstein P, Nagata S. Molecular cloning and expression of the Fas ligand, a novel member of the tumor necrosis factor family. Cell 1993; 75:1169-1178.

14 Wiley SR, Schooley K, Smolak PJ, et al. Identification and characterization of a new member of the TNF family that induces apoptosis. Immunity 1995; 3:673-682.

15 Pitti RM, Marsters SA, Ruppert S, et al. Induction of apoptosis by Apo-2 ligand, a new member of the tumor necrosis factor cytokine family. J Biol Chem 1996; 271:12687-12690.

16 Smith CA, Farrah T, Goodwin RG. The TNF receptor superfamily of cellular and viral proteins: activation, costimulation, and death. Cell 1994; 76:959-962.

17 Tartaglia LA, Ayres TM, Wong GH, Goeddel DV. A novel domain within the $55 \mathrm{kd}$ TNF receptor signals cell death. Cell 1993; 74:845-853.

18 Medema JP, Scaffidi C, Kischkel FC, et al. FLICE is activated by association with the CD95 death-inducing signaling complex (DISC). EMBO J 1997; 16:2794-2804.

19 Chinnaiyan AM, O'Rourke K, Tewari M, Dixit VM. FADD, a novel death domain-containing protein, interacts with the death 
domain of Fas and initiates apoptosis. Cell 1995; 81:505-512.

20 Kabra NH, Kang C, Hsing LC, Zhang J, Winoto A. T cell-specific FADD-deficient mice: FADD is required for early $\mathrm{T}$ cell development. Proc Natl Acad Sci USA 2001; 98:6307-6312.

21 Muzio M, Chinnaiyan AM, Kischkel FC, et al. FLICE, a novel FADD-homologous ICE/CED-3-like protease, is recruited to the CD95 (Fas/APO-1) death-inducing signaling complex. Cell 1996; 85:817-827.

22 Boldin MP, Goncharov TM, Goltsev YV, Wallach D. Involvement of MACH, a novel MORT1/FADD-interacting protease, in Fas/APO-1- and TNF receptor-induced cell death. Cell 1996; 85:803-815.

23 Wajant H, Johannes FJ, Haas E, et al. Dominant-negative FADD inhibits TNFR60-, Fas/Apo1- and TRAIL-R/Apo2-mediated cell death but not gene induction. Curr Biol 1998; 8:113-116.

24 Zhang J, Cado D, Chen A, Kabra NH, Winoto A. Fas-mediated apoptosis and activation-induced T-cell proliferation are defective in mice lacking FADD/Mort1. Nature 1998; 392:296-300.

25 Stanger BZ, Leder P, Lee TH, Kim E, Seed B. RIP: a novel protein containing a death domain that interacts with Fas/APO-1 (CD95) in yeast and causes cell death. Cell 1995; 81:513-523.

26 Ahmad M, Srinivasula SM, Wang L, et al. CRADD, a novel human apoptotic adaptor molecule for caspase-2, and FasL/tumor necrosis factor receptor-interacting protein RIP. Cancer Res 1997; 57:615-619.

27 Duan H, Orth K, Chinnaiyan AM, et al. ICE-LAP6, a novel member of the ICE/Ced-3 gene family, is activated by the cytotoxic T cell protease granzyme B. J Biol Chem 1996; 271:1672016724.

28 Wang R, Zhang L, Zhang X, et al. Differential regulation of the expression of CD95 ligand, receptor activator of nuclear factor-kappa B ligand (RANKL), TNF-related apoptosis-inducing ligand (TRAIL), and TNF-alpha during T cell activation. J Immunol 2001; 166:1983-1990.

29 Pitti RM, Marsters SA, Lawrence DA, et al. Genomic amplification of a decoy receptor for Fas ligand in lung and colon cancer. Nature 1998; 396:699-703.

30 Irmler M, Thome M, Hahne M, et al. Inhibition of death receptor signals by cellular FLIP. Nature 1997; 388:190-195.

31 Goltsev YV, Kovalenko AV, Arnold E, et al. CASH, a novel caspase homologue with death effector domains. J Biol Chem 1997; 272:19641-19644.

32 Han DK, Chaudhary PM, Wright ME, et al. MRIT, a novel deatheffector domain-containing protein, interacts with caspases and BclXL and initiates cell death. Proc Natl Acad Sci USA 1997; 94:11333-11338.

33 Inohara N, Koseki T, Hu Y, Chen S, Nunez G. CLARP, a death effector domain-containing protein interacts with caspase- 8 and regulates apoptosis. Proc Natl Acad Sci USA 1997; 94:1071710722.

34 Holler N, Zaru R, Micheau O, et al. Fas triggers an alternative, caspase-8-independent cell death pathway using the kinase RIP as effector molecule. Nat Immunol 2000; 1:489-495.

35 Siegel RM, Chan FK, Chun HJ, Lenardo MJ. The multifaceted role of Fas signaling in immune cell homeostasis and autoimmunity. Nat Immunol 2000; 1:469-474.

36 Pan G, Ni J, Wei YF, et al. An antagonist decoy receptor and a death domain-containing receptor for TRAIL. Science 1997; 277:815-818.
37 Walczak H, Degli-Esposti MA, Johnson RS, et al. TRAIL-R2: a novel apoptosis-mediating receptor for TRAIL. EMBO J 1997; 16:5386-5397.

38 Screaton GR, Mongkolsapaya J, Xu XN, et al. TRICK2, a new alternatively spliced receptor that transduces the cytotoxic signal from TRAIL. Curr Biol 1997; 7:693-696.

39 MacFarlane M, Ahmad M, Srinivasula SM, et al. Identification and molecular cloning of two novel receptors for the cytotoxic ligand TRAIL. J Biol Chem 1997; 272:25417-25420.

40 Marsters SA, Sheridan JP, Pitti RM, et al. A novel receptor for Apo2L/TRAIL contains a truncated death domain. Curr Biol 1997; 7:1003-1006.

41 Degli-Esposti MA, Dougall WC, Smolak PJ, et al. The novel receptor TRAIL-R4 induces NF-kappaB and protects against TRAIL-mediated apoptosis, yet retains an incomplete death domain. Immunity 1997; 7:813-820.

42 Pan G, Ni J, Yu G, Wei YF, Dixit VM. TRUNDD, a new member of the TRAIL receptor family that antagonizes TRAIL signalling. FEBS Lett 1998; 424:41-45.

43 Simonet WS, Lacey DL, Dunstan CR, et al. Osteoprotegerin: a novel secreted protein involved in the regulation of bone density. Cell 1997; 89:309-319.

44 Nagata S. Steering anti-cancer drugs away from the TRAIL. Nat Med 2000; 6:502-503.

45 Jo M, Kim TH, Seol DW, et al. Apoptosis induced in normal human hepatocytes by tumor necrosis factor-related apoptosisinducing ligand. Nat Med 2000; 6:564-567.

46 Lawrence D, Shahrokh Z, Marsters S, et al. Differential hepatocyte toxicity of recombinant Apo2L/TRAIL versions. Nat Med 2001; 7:383-385.

47 Robertson NM, Zangrilli JG, Steplewski A, et al. Differential expression of TRAIL and TRAIL receptors in allergic asthmatics following segmental antigen challenge: evidence for a role of TRAIL in eosinophil survival. J Immunol 2002; 169:59865996.

48 Himmler A, Maurer-Fogy I, Kronke M, et al. Molecular cloning and expression of human and rat tumor necrosis factor receptor chain (p60) and its soluble derivative, tumor necrosis factorbinding protein. DNA Cell Biol 1990; 9:705-715.

49 Loetscher H, Pan YC, Lahm HW, et al. Molecular cloning and expression of the human $55 \mathrm{kd}$ tumor necrosis factor receptor. Cell 1990; 61:351-359.

50 Nophar Y, Kemper O, Brakebusch C, et al. Soluble forms of tumor necrosis factor receptors (TNF-Rs). The cDNA for the type I TNF-R, cloned using amino acid sequence data of its soluble form, encodes both the cell surface and a soluble form of the receptor. EMBO J 1990; 9:3269-3278.

51 Gray PW, Barrett K, Chantry D, Turner M, Feldmann M. Cloning of human tumor necrosis factor (TNF) receptor cDNA and expression of recombinant soluble TNF-binding protein. Proc Natl Acad Sci USA 1990; 87:7380-7384.

52 Schall TJ, Lewis M, Koller KJ, et al. Molecular cloning and expression of a receptor for human tumor necrosis factor. Cell 1990; 61:361-370.

53 Micheau O, Tschopp J. Induction of TNF receptor I-mediated apoptosis via two sequential signaling complexes. Cell 2003; 114:181-190.

54 Chang L, Kamata H, Solinas G, et al. The E3 ubiquitin ligase Itch couples JNK activation to TNFalpha-induced cell death by 
inducing c-FLIP(L) turnover. Cell 2006; 124:601-613.

55 Sharief MK, Hentges R. Association between tumor necrosis factor-alpha and disease progression in patients with multiple sclerosis. N Engl J Med 1991; 325:467-472.

56 Liu J, Marino MW, Wong G, et al. TNF is a potent anti-inflammatory cytokine in autoimmune-mediated demyelination. Nat Med 1998; 4:78-83.

57 Abe T, Takeuchi T. Rheumatoid arthritis and tumor necrosis factor alpha. Autoimmunity 2001; 34:291-303.

58 Tsujimoto Y, Cossman J, Jaffe E, Croce CM. Involvement of the bcl-2 gene in human follicular lymphoma. Science 1985; 228:1440-1443.

59 Bakhshi A, Jensen JP, Goldman P, et al. Cloning the chromosomal breakpoint of $\mathrm{t}(14 ; 18)$ human lymphomas: clustering around $\mathrm{JH}$ on chromosome 14 and near a transcriptional unit on 18. Cell 1985; 41:899-906.

60 Cleary ML, Sklar J. Nucleotide sequence of a t $(14 ; 18)$ chromosomal breakpoint in follicular lymphoma and demonstration of a breakpoint-cluster region near a transcriptionally active locus on chromosome 18. Proc Natl Acad Sci USA 1985; 82:74397443.

61 Boise LH, Gonzalez-Garcia M, Postema CE, et al. bcl-x, a bcl-2related gene that functions as a dominant regulator of apoptotic cell death. Cell 1993; 74:597-608.

62 Gibson L, Holmgreen SP, Huang DC, et al. bcl-w, a novel member of the bcl-2 family, promotes cell survival. Oncogene 1996; 13:665-675.

$63 \mathrm{Ke} \mathrm{N}$, Godzik A, Reed JC. Bcl-B, a novel Bcl-2 family member that differentially binds and regulates Bax and Bak. J Biol Chem 2001; 276:12481-12484.

64 Lin EY, Orlofsky A, Wang HG, Reed JC, Prystowsky MB. A1, a Bcl-2 family member, prolongs cell survival and permits myeloid differentiation. Blood 1996; 87:983-992.

65 Kozopas KM, Yang T, Buchan HL, Zhou P, Craig RW. MCL1, a gene expressed in programmed myeloid cell differentiation, has sequence similarity to BCL2. Proc Natl Acad Sci USA 1993; 90:3516-3520.

66 Oltvai ZN, Milliman CL, Korsmeyer SJ. Bcl-2 heterodimerizes in vivo with a conserved homolog, Bax, that accelerates programmed cell death. Cell 1993; 74:609-619.

67 Chittenden T, Flemington C, Houghton AB, et al. A conserved domain in Bak, distinct from $\mathrm{BH} 1$ and $\mathrm{BH} 2$, mediates cell death and protein binding functions. EMBO J 1995; 14:5589-5596.

68 Kiefer MC, Brauer MJ, Powers VC, et al. Modulation of apoptosis by the widely distributed Bcl-2 homologue Bak. Nature 1995; 374:736-739.

69 Hsu SY, Hsueh AJ. A splicing variant of the Bcl-2 member Bok with a truncated $\mathrm{BH} 3$ domain induces apoptosis but does not dimerize with antiapoptotic Bcl-2 proteins in vitro. JBiol Chem 1998; 273:30139-30146.

70 Guo B, Godzik A, Reed JC. Bcl-G, a novel pro-apoptotic member of the Bcl-2 family. JBiol Chem 2001; 276:2780-2785.

71 Yang E, Zha J, Jockel J, et al. Bad, a heterodimeric partner for Bcl-XL and Bcl-2, displaces Bax and promotes cell death. Cell 1995; 80 (2):285-291.

72 Wang K, Yin XM, Chao DT, Milliman CL, Korsmeyer SJ. BID: a novel BH3 domain-only death agonist. Genes Dev 1996; 10:2859-2869.

73 O'Connor L, Strasser A, O'Reilly LA, et al. Bim: a novel mem- ber of the Bcl-2 family that promotes apoptosis. EMBO J 1998; 17:384-395.

74 Boyd JM, Gallo GJ, Elangovan B, et al. Bik, a novel death-inducing protein shares a distinct sequence motif with Bcl-2 family proteins and interacts with viral and cellular survival-promoting proteins. Oncogene 1995; 11:1921-1928.

75 Oda E, Ohki R, Murasawa H, et al. Noxa, a BH3-only member of the Bcl-2 family and candidate mediator of p53-induced apoptosis. Science 2000; 288:1053-1058.

$76 \mathrm{Yu}$ J, Zhang L, Hwang PM, Kinzler KW, Vogelstein B. PUMA induces the rapid apoptosis of colorectal cancer cells. Mol Cell 2001; 7:673-682.

77 Hegde R, Srinivasula SM, Ahmad M, Fernandes-Alnemri T, Alnemri ES. Blk, a BH3-containing mouse protein that interacts with Bcl-2 and Bcl-xL, is a potent death agonist. J Biol Chem 1998; 273:7783-7786.

78 Puthalakath H, Villunger A, O'Reilly LA, et al. Bmf: a proapoptotic $\mathrm{BH} 3$-only protein regulated by interaction with the myosin $\mathrm{V}$ actin motor complex, activated by anoikis. Science (New York, NY) 2001; 293:1829-1832.

79 Inohara N, Ding L, Chen S, Nunez G. harakiri, a novel regulator of cell death, encodes a protein that activates apoptosis and interacts selectively with survival-promoting proteins Bcl-2 and Bcl-X(L). EMBO J 1997; 16:1686-1694.

80 Danial NN, Korsmeyer SJ. Cell death: critical control points. Cell 2004; 116:205-219.

81 Lindsten T, Ross AJ, King A, et al. The combined functions of proapoptotic Bcl-2 family members bak and bax are essential for normal development of multiple tissues. Mol Cell 2000; 6:1389-1399.

82 Cheng EH, Wei MC, Weiler S, et al. BCL-2, BCL-X(L) sequester $\mathrm{BH} 3$ domain-only molecules preventing BAX- and BAK-mediated mitochondrial apoptosis. Mol Cell 2001; 8:705-711.

83 Huang DC, Strasser A. BH3-Only proteins-essential initiators of apoptotic cell death. Cell 2000; 103:839-842.

84 Cartron PF, Gallenne T, Bougras G, et al. The first alpha helix of Bax plays a necessary role in its ligand-induced activation by the BH3-only proteins Bid and PUMA. Mol Cell 2004; 16:807818.

85 Kuwana T, Bouchier-Hayes L, Chipuk JE, et al. BH3 domains of $\mathrm{BH} 3$-only proteins differentially regulate Bax-mediated mitochondrial membrane permeabilization both directly and indirectly. Mol Cell 2005; 17:525-535.

86 Chen L, Willis SN, Wei A, et al. Differential targeting of prosurvival Bcl-2 proteins by their BH3-only ligands allows complementary apoptotic function. Mol Cell 2005; 17:393-403.

87 Willis SN, Fletcher JI, Kaufmann T, et al. Apoptosis initiated when BH3 ligands engage multiple Bcl-2 homologs, not Bax or Bak. Science (New York, NY) 2007; 315:856-859.

88 Liu X, Kim CN, Yang J, Jemmerson R, Wang X. Induction of apoptotic program in cell-free extracts: requirement for dATP and cytochrome $c$. Cell 1996; 86:147-157.

89 Zou H, Henzel WJ, Liu X, Lutschg A, Wang X. Apaf-1, a human protein homologous to $C$. elegans CED-4, participates in cytochrome $c$-dependent activation of caspase-3. Cell 1997; 90:405-413.

90 Zou H, Li Y, Liu X, Wang X. An APAF-1.cytochrome $c$ multimeric complex is a functional apoptosome that activates procaspase-9. J Biol Chem 1999; 274:11549-11556. 
91 Zhang XJ, Yang L, Zhao Q, et al. Induction of acetylcholinesterase expression during apoptosis in various cell types. Cell Death Differ 2002; 9:790-800.

92 Park SE, Kim ND, Yoo YH. Acetylcholinesterase plays a pivotal role in apoptosome formation. Cancer Res 2004; 64:26522655.

93 Park SE, Yoo YH, Kim ND. Role of acetylcholinesterase in apoptosome formation during apoptosis. AACR Meeting Abstracts 2007; 48:1219.

94 Chandra D, Bratton SB, Person MD, et al. Intracellular nucleotides act as critical prosurvival factors by binding to cytochrome $C$ and inhibiting apoptosome. Cell 2006; 125:1333-1346.

95 Yoshida H, Kong YY, Yoshida R, et al. Apaf1 is required for mitochondrial pathways of apoptosis and brain development. Cell 1998; 94:739-750.

96 Hao Z, Duncan GS, Chang CC, et al. Specific ablation of the apoptotic functions of cytochrome $C$ reveals a differential requirement for cytochrome $\mathrm{C}$ and Apaf-1 in apoptosis. Cell 2005; 121:579-591.

97 Uren AG, Pakusch M, Hawkins CJ, Puls KL, Vaux DL. Cloning and expression of apoptosis inhibitory protein homologs that function to inhibit apoptosis and/or bind tumor necrosis factor receptor-associated factors. Proc Natl Acad Sci USA 1996; 93:4974-4978.

98 Duckett CS, Nava VE, Gedrich RW, et al. A conserved family of cellular genes related to the baculovirus iap gene and encoding apoptosis inhibitors. EMBO J 1996; 15:2685-2694.

99 Deveraux QL, Takahashi R, Salvesen GS, Reed JC. X-linked IAP is a direct inhibitor of cell-death proteases. Nature 1997; 388:300-304.

100 Ambrosini G, Adida C, Altieri DC. A novel anti-apoptosis gene, survivin, expressed in cancer and lymphoma. Nat Medicine 1997; 3:917-921.

101 Chai J, Du C, Wu JW, et al. Structural and biochemical basis of apoptotic activation by Smac/DIABLO. Nature 2000; 406:855862.

102 Verhagen AM, Ekert PG, Pakusch M, et al. Identification of DIA$\mathrm{BLO}$, a mammalian protein that promotes apoptosis by binding to and antagonizing IAP proteins. Cell 2000; 102:43-53.

103 Susin SA, Lorenzo HK, Zamzami N, et al. Molecular characterization of mitochondrial apoptosis-inducing factor. Nature 1999; 397:441-446.

104Luo X, Budihardjo I, Zou H, Slaughter C, Wang X. Bid, a Bcl2 interacting protein, mediates cytochrome $c$ release from mitochondria in response to activation of cell surface death receptors. Cell 1998; 94:481-490.

105 Chang HY, Nishitoh H, Yang X, Ichijo H, Baltimore D. Activation of apoptosis signal-regulating kinase 1 (ASK1) by the adapter protein Daxx. Science 1998; 281:1860-1863.

106Sarin A, Williams MS, Alexander-Miller MA, et al. Target cell lysis by CTL granule exocytosis is independent of ICE/Ced-3 family proteases. Immunity 1997; 6:209-215.

107Fan Z, Beresford PJ, Oh DY, Zhang D, Lieberman J. Tumor suppressor NM23-H1 is a granzyme A-activated DNase during CTL-mediated apoptosis, and the nucleosome assembly protein SET is its inhibitor. Cell 2003; 112:659-672.

108 Yamada M, Hirasawa A, Shiojima S, Tsujimoto G. Granzyme A mediates glucocorticoid-induced apoptosis in leukemia cells. FASEB J 2003; 17:1712-1714.
109Gil-Parrado S, Fernandez-Montalvan A, Assfalg-Machleidt I, et al. Ionomycin-activated calpain triggers apoptosis. A probable role for Bcl-2 family members. J Biol Chem 2002; 277:2721727226.

110 Wood DE, Thomas A, Devi LA, et al. Bax cleavage is mediated by calpain during drug-induced apoptosis. Oncogene 1998; 17:1069-1078.

111 Altznauer F, Conus S, Cavalli A, Folkers G, Simon HU. Calpain-1 regulates Bax and subsequent Smac-dependent caspase-3 activation in neutrophil apoptosis. J Biol Chem 2004; 279:59475957.

112 Yousefi S, Perozzo R, Schmid I, et al. Calpain-mediated cleavage of Atg5 switches autophagy to apoptosis. Nat Cell Biol 2006; 8:1124-1132.

113 Neumar RW, Xu YA, Gada H, Guttmann RP, Siman R. Cross-talk between calpain and caspase proteolytic systems during neuronal apoptosis. J Biol Chem 2003; 278:14162-14167.

114 Nakagawa T, Yuan J. Cross-talk between two cysteine protease families. Activation of caspase- 12 by calpain in apoptosis. J Cell Biol 2000; 150:887-894.

115 Sebzda E, Mariathasan S, Ohteki T, et al. Selection of the T cell repertoire. Annu Rev Immunol 1999; 17:829-874.

116Lamhamedi-Cherradi SE, Zheng SJ, Maguschak KA, Peschon J, Chen YH. Defective thymocyte apoptosis and accelerated autoimmune diseases in TRAIL-/- mice. Nat Immunol 2003; 4:255-260.

117 Sedger LM, Glaccum MB, Schuh JC, et al. Characterization of the in vivo function of TNF-alpha-related apoptosis-inducing ligand, TRAIL/Apo2L, using TRAIL/Apo2L gene-deficient mice. Eur J Immunol 2002; 32:2246-2254.

118 Cretney E, Uldrich AP, Berzins SP, et al. Normal thymocyte negative selection in TRAIL-deficient mice. J Exp Med 2003; 198:491-496.

119 Simon AK, Williams O, Mongkolsapaya J, et al. Tumor necrosis factor-related apoptosis-inducing ligand in T cell development: sensitivity of human thymocytes. Proc Natl Acad Sci USA 2001; 98:5158-5163.

120 Pfeffer K, Matsuyama T, Kundig TM, et al. Mice deficient for the $55 \mathrm{kd}$ tumor necrosis factor receptor are resistant to endotoxic shock, yet succumb to L. monocytogenes infection. Cell 1993; 73:457-467.

121 Rothe J, Lesslauer W, Lotscher H, et al. Mice lacking the tumour necrosis factor receptor 1 are resistant to TNF-mediated toxicity but highly susceptible to infection by Listeria monocytogenes. Nature 1993; 364:798-802.

122 Erickson SL, de Sauvage FJ, Kikly K, et al. Decreased sensitivity to tumour-necrosis factor but normal T-cell development in TNF receptor-2-deficient mice. Nature 1994; 372:560-563.

123 Page DM, Roberts EM, Peschon JJ, Hedrick SM. TNF receptordeficient mice reveal striking differences between several models of thymocyte negative selection. J Immunol 1998; 160:120133.

124 Villunger A, Marsden VS, Zhan Y, et al. Negative selection of semimature CD4(+)8(-)HSA+ thymocytes requires the $\mathrm{BH} 3$-only protein Bim but is independent of death receptor signaling. Proc Natl Acad Sci USA 2004; 101:7052-7057.

125 Singer GG, Abbas AK. The fas antigen is involved in peripheral but not thymic deletion of $\mathrm{T}$ lymphocytes in $\mathrm{T}$ cell receptor transgenic mice. Immunity 1994; 1:365-371. 
126Sytwu HK, Liblau RS, McDevitt HO. The roles of Fas/APO-1 (CD95) and TNF in antigen-induced programmed cell death in T cell receptor transgenic mice. Immunity 1996; 5:17-30.

127 Adachi M, Suematsu S, Suda T, et al. Enhanced and accelerated lymphoproliferation in Fas-null mice. Proc Natl Acad Sci USA 1996; 93:2131-2136.

128Sidman CL, Marshall JD, Von Boehmer H. Transgenic T cell receptor interactions in the lymphoproliferative and autoimmune syndromes of lpr and gld mutant mice. Eur J Immunol 1992; 22:499-504.

129Castro JE, Listman JA, Jacobson BA, et al. Fas modulation of apoptosis during negative selection of thymocytes. Immunity 1996; 5:617-627.

130 Kishimoto H, Surh CD, Sprent J. A role for Fas in negative selection of thymocytes in vivo. J Exp Med 1998; 187:1427-1438.

131 Probert L, Keffer J, Corbella P, et al. Wasting, ischemia, and lymphoid abnormalities in mice expressing T cell-targeted human tumor necrosis factor transgenes. J Immunol 1993; 151:18941906.

132 Newton K, Harris AW, Bath ML, Smith KG, Strasser A. A dominant interfering mutant of FADD/MORT1 enhances deletion of autoreactive thymocytes and inhibits proliferation of mature $\mathrm{T}$ lymphocytes. EMBO J 1998; 17:706-718.

133 Hacker G, Hawkins CJ, Smith KG, Vaux DL. Effects of viral inhibitors of apoptosis in models of mammalian cell death. Behring Inst Mitt 1996 (97):118-126.

134 Ashwell JD, Cunningham RE, Noguchi PD, Hernandez D. Cell growth cycle block of $\mathrm{T}$ cell hybridomas upon activation with antigen. J Exp Med 1987; 165:173-194.

135 Shi YF, Sahai BM, Green DR. Cyclosporin A inhibits activationinduced cell death in T-cell hybridomas and thymocytes. Nature 1989; 339:625-626.

136Ucker DS, Ashwell JD, Nickas G. Activation-driven T cell death. I. Requirements for de novo transcription and translation and association with genome fragmentation. J Immunol 1989; 143:3461-3469.

137Fisher GH, Rosenberg FJ, Straus SE, et al. Dominant interfering Fas gene mutations impair apoptosis in a human autoimmune lymphoproliferative syndrome. Cell 1995; 81:935-946.

138Dhein J, Walczak H, Baumler C, Debatin KM, Krammer PH. Autocrine T-cell suicide mediated by APO-1/(Fas/CD95). Nature 1995; 373:438-441.

139Brunner T, Mogil RJ, LaFace D, et al. Cell-autonomous Fas (CD95)/Fas-ligand interaction mediates activation-induced apoptosis in T-cell hybridomas. Nature 1995; 373:441-444.

140Ju ST, Panka DJ, Cui H, et al. Fas(CD95)/FasL interactions required for programmed cell death after T-cell activation. Nature 1995; 373:444-448.

141 Katsikis PD, Garcia-Ojeda ME, Wunderlich ES, et al. Activation-induced peripheral blood T cell apoptosis is Fas independent in HIV-infected individuals. Int Immunol 1996; 8:1311-1317.

142 Katsikis PD, Garcia-Ojeda ME, Torres-Roca JF, et al. Interleukin-1 beta converting enzyme-like protease involvement in Fasinduced and activation-induced peripheral blood $\mathrm{T}$ cell apoptosis in HIV infection. TNF-related apoptosis-inducing ligand can mediate activation-induced T cell death in HIV infection. J Exp Med 1997; 186:1365-1372.

143 Wang J, Stohlman SA, Dennert G. TCR cross-linking induces CTL death via internal action of TNF. J Immunol 1994; 152:3824-
3832.

144Packham G, Lahti JM, Fee BE, et al. Fas activates NF-kappaB and induces apoptosis in T-cell lines by signaling pathways distinct from those induced by TNF-alpha. Cell Death Differ 1997; 4:130-139.

145Zheng L, Fisher G, Miller RE, et al. Induction of apoptosis in mature T cells by tumour necrosis factor. Nature 1995; 377:348351.

146Gorak-Stolinska P, Truman JP, Kemeny DM, Noble A. Activation-induced cell death of human T-cell subsets is mediated by Fas and granzyme B but is independent of TNF-alpha. J Leukoc Biol 2001; 70:756-766.

147Bottomly K. A functional dichotomy in CD4+ T lymphocytes. Immunol Today 1988; 9:268-274.

148Mosmann TR, Coffman RL. TH1 and TH2 cells: different patterns of lymphokine secretion lead to different functional properties. Annu Rev Immunol 1989; 7:145-173.

149Roberts AI, Devadas S, Zhang X, et al. The role of activationinduced cell death in the differentiation of T-helper-cell subsets. Immunol Res 2003; 28:285-293.

150Zhang XR, Zhang LY, Devadas S, et al. Reciprocal expression of TRAIL and CD95L in Th1 and Th2 cells: role of apoptosis in T helper subset differentiation. Cell Death Differ 2003; 10:203210.

151 Ramsdell F, Seaman MS, Miller RE, et al. Differential ability of Th1 and Th2 T cells to express Fas ligand and to undergo activation-induced cell death. Int Immunol 1994; 6:1545-1553.

152 Varadhachary AS, Perdow SN, Hu C, Ramanarayanan M, Salgame P. Differential ability of T cell subsets to undergo activation-induced cell death. Proc Natl Acad Sci USA 1997; 94:5778-5783.

153 Accornero P, Radrizzani M, Delia D, et al. Differential susceptibility to HIV-GP120-sensitized apoptosis in CD4+ T-cell clones with different T-helper phenotypes: role of CD95/CD95L interactions. Blood 1997; 89:558-569.

154Zhang X, Brunner T, Carter L, et al. Unequal death in T helper cell (Th) 1 and Th2 effectors: Th1, but not Th2, effectors undergo rapid Fas/FasL-mediated apoptosis. J Exp Med 1997; 185:18371849.

155 Varadhachary AS, Peter ME, Perdow SN, Krammer PH, Salgame P. Selective up-regulation of phosphatidylinositol 3'-kinase activity in Th 2 cells inhibits caspase- 8 cleavage at the death-inducing complex: a mechanism for Th2 resistance from Fas-mediated apoptosis. J Immunol 1999; 163:4772-4779.

156Varadhachary AS, Edidin M, Hanlon AM, et al. Phosphatidylinositol 3'-kinase blocks CD95 aggregation and caspase- 8 cleavage at the death-inducing signaling complex by modulating lateral diffusion of CD95. J Immunol 2001; 166:6564-6569.

157Devadas S, Das J, Liu C, et al. Granzyme B is critical for T cell receptor-induced cell death of type 2 helper T cells. Immunity 2006; 25:237-247.

158Harrington LE, Hatton RD, Mangan PR, et al. Interleukin 17producing CD4+ effector T cells develop via a lineage distinct from the T helper type 1 and 2 lineages. Nat Immunol 2005; 6:1123-1132.

159Park H, Li Z, Yang XO, et al. A distinct lineage of CD4 T cells regulates tissue inflammation by producing interleukin 17 . Nat Immunol 2005; 6:1133-1141.

160Zimmermann C, Rawiel M, Blaser C, Kaufmann M, Pircher H. 
Homeostatic regulation of CD8 $+\mathrm{T}$ cells after antigen challenge in the absence of Fas (CD95). Eur J Immunol 1996; 26:29032910.

161 Speiser DE, Sebzda E, Ohteki T, et al. Tumor necrosis factor receptor p55 mediates deletion of peripheral cytotoxic T lymphocytes in vivo. Eur J Immunol 1996; 26:3055-3060.

162 Janssen EM, Droin NM, Lemmens EE, et al. CD4+ T-cell help controls CD8+ T-cell memory via TRAIL-mediated activationinduced cell death. Nature 2005; 434:88-93.

163Laforge M, Bidere N, Carmona S, et al. Apoptotic death concurrent with CD3 stimulation in primary human CD8+ T lymphocytes: a role for endogenous granzyme B. J Immunol 2006; 176:3966-3977.

164Sad S, Marcotte R, Mosmann TR. Cytokine-induced differentiation of precursor mouse CD8+ T cells into cytotoxic CD8+ T cells secreting Th1 or Th2 cytokines. Immunity 1995; 2:271-279.

165Croft M, Carter L, Swain SL, Dutton RW. Generation of polarized antigen-specific CD8 effector populations: reciprocal action of interleukin (IL)-4 and IL-12 in promoting type 2 versus type 1 cytokine profiles. J Exp Med 1994; 180:1715-1728.

166Cronin DC II, Stack R, Fitch FW. IL-4-producing CD8+ T cell clones can provide B cell help. J Immunol 1995; 154:31183127.

167Noble A, Macary PA, Kemeny DM. IFN-gamma and IL-4 regulate the growth and differentiation of $\mathrm{CD} 8+\mathrm{T}$ cells into subpopulations with distinct cytokine profiles. J Immunol 1995; 155:2928-2937.

168MacAry PA, Holmes BJ, Kemeny DM. Ovalbumin-specific, MHC class I-restricted, alpha beta-positive, Tc1 and Tc0 CD8+ $\mathrm{T}$ cell clones mediate the in vivo inhibition of rat IgE. J Immunol 1998; 160:580-587.

169Maggi E, Giudizi MG, Biagiotti R, et al. Th2-like CD8+ T cells showing $\mathrm{B}$ cell helper function and reduced cytolytic activity in human immunodeficiency virus type 1 infection. J Exp Med 1994; 180:489-495.

170 Salgame $\mathrm{P}$, Abrams JS, Clayberger C, et al. Differing lymphokine profiles of functional subsets of human CD4 and CD8 T cell clones. Science (New York, NY) 1991; 254:279-282.

171 Vukmanovic-Stejic M, Vyas B, Gorak-Stolinska P, Noble A, Kemeny DM. Human Tc1 and Tc2/Tc0 CD8 T-cell clones display distinct cell surface and functional phenotypes. Blood 2000; 95:231-240.

172 Seino K, Harada M, Taniguchi M. NKT cells are relatively resistant to apoptosis. Trends Immunol 2004; 25:219-221.

173 Banz A, Pontoux C, Papiernik M. Modulation of Fas-dependent apoptosis: a dynamic process controlling both the persistence and death of CD4 regulatory T cells and effector T cells. J Immunol 2002; 169:750-757.

174Fritzsching B, Oberle N, Eberhardt N, et al. In contrast to effector T cells, CD4+CD25+FoxP3+ regulatory $\mathrm{T}$ cells are highly susceptible to CD95 ligand- but not to TCR-mediated cell death. J Immunol 2005; 175:32-36.

175Berard M, Casamayor-Palleja M, Billian G, et al. Activation sensitizes human memory B cells to B-cell receptor-induced apoptosis. Immunology 1999; 98:47-54.

176Donjerkovic D, Scott DW. Activation-induced cell death in B lymphocytes. Cell Res 2000; 10:179-192.

177Deming PB, Rathmell JC. Mitochondria, cell death, and B cell tolerance. Curr Dir Autoimmun 2006; 9:95-119.

178 Yoshida T, Higuchi T, Hagiyama H, et al. Rapid B cell apoptosis induced by antigen receptor ligation does not require Fas (CD95/ APO-1), the adaptor protein FADD/MORT1 or CrmA-sensitive caspases but is defective in both MRL-+/+ and MRL-lpr/lpr mice. Int Immunol 2000; 12:517-526.

179Daniel PT, Oettinger U, Mapara MY, et al. Activation and activation-induced death of human tonsillar B cells and Burkitt lymphoma cells: lack of CD95 (Fas/APO-1) ligand expression and function. Eur J Immunol 1997; 27:1029-1034.

180 Besnault L, Schrantz N, Auffredou MT, et al. B cell receptor cross-linking triggers a caspase-8-dependent apoptotic pathway that is independent of the death effector domain of Fas-associated death domain protein. J Immunol 2001; 167:733-740.

181 Kroesen BJ, Pettus B, Luberto C, et al. Induction of apoptosis through B-cell receptor cross-linking occurs via de novo generated C16-ceramide and involves mitochondria. J Biol Chem 2001; 276:13606-13614.

182 Bouchon A, Krammer PH, Walczak H. Critical role for mitochondria in B cell receptor-mediated apoptosis. Eur J Immunol 2000; 30:69-77.

183 Berard M, Mondiere P, Casamayor-Palleja M, et al. Mitochondria connects the antigen receptor to effector caspases during $\mathrm{B}$ cell receptor-induced apoptosis in normal human B cells. J Immunol 1999; 163:4655-4662.

184Doi T, Motoyama N, Tokunaga A, Watanabe T. Death signals from the $\mathrm{B}$ cell antigen receptor target mitochondria, activating necrotic and apoptotic death cascades in a murine B cell line, WEHI-231. Int Immunol 1999; 11:933-941.

$185 \mathrm{Katz}$ E, Deehan MR, Seatter S, et al. B cell receptor-stimulated mitochondrial phospholipase A2 activation and resultant disruption of mitochondrial membrane potential correlate with the induction of apoptosis in WEHI-231 B cells. J Immunol 2001; 166:137-147. 